\title{
Effect of Time Management Training program on Nurses' Daily Time Wasters
}

\author{
Nadia M. A. Saleh ${ }^{1}$ \& Eman M. A. El Shazly ${ }^{2}$. \\ 1. Assistant Professor of Nursing Administration, Faculty of Nursing, Sohag University, Egypt, \\ ${ }^{2 .}$ Lecturer of Nursing Administration, Faculty of Nursing, Qena University, Egypt.
}

\begin{abstract}
Background: Time management training program concerned with giving insight into time wasters, changing time spending, and increasing the efficiency of workday for staff by learning them planning their work by prioritize activities, and manage emergency and unexpected tasks. Study aims to evaluate the effect of designed program of time management on daily time waters for nurses'. The subjects: No. = (118) staff nurses. Setting; Sohag \& Qena Universities Hospitals. Tools; consists of 1) Time management questionnaire include personal characteristics and Time management scale; 2) Time waster Questionnaire. Results: mean score of total time managements at pre intervention (55.95 \pm 8.41$)$, post $(59.95 \pm 7.6)$, and follow up (63.67 \pm 9.8$)$. Mean score of total time wasters at pre intervention (41.34 \pm 9.46$)$, post $(32.32 \pm 7.86)$, and follow up (24.93 \pm 5.98$)$. Conclusion; there were high negative correlation between time management and time waster scores. There were high significant differences between studied nurses at pre, post and follow up intervention related goal setting, managing interruptions, procrastination time management, and time waster domains (internal and external). Recommendations: Training programs on time management should be provided for nursing staff at their various levels, policies, rules and regulations must be clarified for employees to preserve time, and records must be organized and coordinated to save time.
\end{abstract}

\section{Keywords: Nurses, Nursing, Training Program, Time Wasters \& Time Management.}

\section{Introduction}

Nurses have a lot of responsibilities in healthcare organization, and a rapid change in the work environment makes it imperative to manage time to achieve these activities. Time is the basic substance of life. It is considered to be a valuable and finite material and is more prone to damage than all the materials because it cannot be replaced or stored. Because once a minute has passed, it's gone forever. So efficient use of time is more important to enable nurses to achieve their professional and personal goals, take control of work and improve quality Time is the most valuable commodity in our life. Time management is the planning of the time available to achieve personal and professional goals, taking into account individual likes, preferences and dislikes. The existence and availability of time determines other sources of development (Ghiasvand, et al., 2017) \& (Kaya, et al., 2012). In order to control and monitor the individuals personal and professional time with productive efficiency, his requires skills in how to set goals, set priorities, acquire planning and organizing skills, and how to reduce wasting time (Gordon \& Borkan, 2014).

Nurses are an indispensable part of any health care system, and the constant and increasing shortage of nurses working smarter is increasing the workload and affecting the quality of care. Nurses working in crowded health facilities must develop their basic skills in managing time well and continuously, and this requires increased pressure for effective time management and important professional satisfaction. The nursing profession requires basic skills in performing various tasks during the day and dealing with time constraints and constant work pressures

(Ancel \& Yilmaz, 2016). Insufficient time management delays patient care and safety (Al-Zoubi 2016).

Nursing staff must be able to manage time effectively to facilitate the realization of the various nursing activities among the basic determinants of effective time management as: clarity of knowledge and competence in the required skills and confidence, early arrival to work and planning for it, inclusion and identification of all activities that must be performed, identification of priority activities, efficient estimation of the time required to complete each activity, and spending the time available consciously. Spending time carefully on emergency and unscheduled activities, and learning to say "no" when you are unable to do things, home life should be better organized and tasks delegated in an effective way are some of the strategies that can be used to enable effective time management. (Nayak, 2019). In order to achieve effective time management, professional and personal management strategies and tools must be used to achieve the most important and priority desired goal, increase productivity and enhance the effectiveness of organizational performance when investing the required activities.

(Tavakoli et al., 2013).

Today, we look forward to continuous learning 
in all health organizations, the application of new strategies at work, preparation and implementation of employee development programs that take into account the value, importance and essence of time. The time management program is of great importance to success in personal life and career success, as it teaches them how to effectively implement their time management strategies and maximize the use of it, and it also helps them make correct and informed decisions, and they can spend most of the time doing important and valuable things high. The program can help in reducing wasted time on unimportant things and wasted energy in it and for the individual to become more creative, more productive and always able to do the right thing at the right time without delay (Zucas, \& David, 2012) \& (Adeyinka 2012).

In order to determine the areas of daily time wasting in your life, you must use the daily time record in a good way, and in order to be able to reduce this waste of time, this is by recording every task or activity that you do every week in detail and then reviewing it constantly to determine how you use your time. Switching from one task to another may result in wasted time, and it can also lead to reduced or lost productivity. A waste of time is any activity that has fewer or no benefits, and this activity usually prevents the nurse from completing the required job or task or prevents achieving the goal (Woodcock, 2014).

There are two types of waste of time: it may be external wastes imposed by people and other things on you such as frequent phones and social visits, you can reduce or eliminate the wasted time you spend on many activities by organizing your work space and workplace that does not need to be overwhelming, providing yourself in an office with a comfortable and sufficient space to do your work, and use the best lighting that you can bear without exaggeration, and the work chair must be comfortable, reduce the time of the phone call by; Focusing on the main cause of the call; You can not answer the phone by leaving a specific message; Get secretarial screen calls for immediate and late response; Talk on the phone while standing; Keep the conversation brief and abbreviated; Set times of the day to receive calls and set times to visit others when you are available. The waste can also be internal for reasons related to your personality, such as procrastination, the inability to say no when you are not able, it is necessary to identify the waters, whether internal or external, to reduce or eliminate them and thus manage time in an effective way (Chapman \& Rupured, 2018).

There are many national and international studies for the Effect of Time Management Training program. For examples in Egypt; Elsabahy, (2015) studied Effect of Time Management Program on Job
Satisfaction for Head Nurses and reported that, there was a significant response related to head nurse's time waster post program implemented; For international studies Nayak, (2019) studied Time Management in Nursing -Hour of need reported that, Good time management techniques and skills are essential for functioning more effectively and to focus on results; Darden, (2015) studied Time Wasting Activities within the Workplace showed that, the manager, supervisor and individual worker identification and elimination of the time-wasting activity can foster an organization that promotes efficiency and increases productivity with increase profitability.

\section{Significance of the study}

Time is very important in our life and wasted time cannot be returned. Therefore, managing time in an effective way helps to equip the personal behavior to meet the demands and make the best use of the available resources, and therefore poor management of time greatly affects every part of our life. Effective management of the time will improve staff performance to the highest level, helping them to prioritize important task and decrease the daily time waster, and helps the organizations to achieving its set goals. The researchers during clinical training for nursing students at General Medical and Surgical departments observed that, most of staff nurses go to their work delayed and cannot finished their day work and they were spent a lot of time in social telephone, eating and visit their friends' and family patients during the work time and does not know importance of time in their work and how can determine the time wasters and how to deal with it effectively. Which encourages the researchers to implement the program to increase participants knowledge about time management and decrease their time wasters at work.

Study aim: To evaluate the effect of a designed program of time management on nurses' daily time wasters.

\section{Study hypothesis}

There is an effect of time management program on nurses' daily time wasters.

\section{Subjects \& Methods}

Design: the study design used was a-Quasiexperimental design.

Setting: The study was conducted at General Medical and Surgical departments at Sohag and Qena universities Hospitals that provides a health services in Upper Egypt.

Subjects: The sample was convenient included all staff nurses they were available at the time of the study in selected departments. The total numbers were (118) staff nurses (56 staff nurse at Sohag 
university hospital and 52 staff nurse at Qena university hospital).

Tools of data collection: Were including two tools:

Tool (1): Time management knowledge questionnaire included two parts:

Part 1: included personal characteristics of the staff nurses as: age, gender, department, educational qualification, Years of experience, and attaining previous training about time management.

Part 2: Time management behavior scale: It was a structured questionnaire format developed by (Sergio 2012) the time management behavior scale used, it consists of twenty five items. Includes; goal setting (6 items); prioritization (4 items); managing interruptions (8 items); procrastination (3 items); and scheduling (4items). Responses was varied as follow: (3) always, (2) sometimes, and (1) never.

Tool (2): Time waster Questionnaire: It was a structured questionnaire format, developed by Elsabahy et al., (2015). It consists of 16 items. It includes internal time wasters ( 8 items) and external time wasters ( 8 items). The possible response for each item as follow: (4) always, (3) often (2) occasionally, and (1) never.

\section{Administrative design}

Official Permissions were obtained from the directors of Sohag and Qena Universities hospitals and Nursing directors to conduct study.

\section{Operational design}

A) Preparatory Phase.

It took about three months from the beginning of May to the end of July (2019) it included reviewing the available literatures related to the study topic, prepares, and translates the study tools and program. The draft of the questionnaire was reviewed for face validity by taking experts opinions through a jury comprised by five experts in nursing administration from faculties of nursing Assuit Universty, and consequently the necessary modification was done.

Designed an educational program was includes; aim and objectives of the program, concept of time, definitions of time, time management, and time wasters, importance of time management, principles of time management barriers for managing time effectively, time management strategies, time wasters and techniques to deal with time wasters.

Implementing activities: time analysis and determine the priorities, design daily and weekly time plan, finding extra time, handling paperwork, effectively delegation, control interruptions, learning to say "No", organizing meeting, procrastination, management by crisis, and motivating of self.

\section{B) Pilot Study}

It was done to identify any misunderstand or obstacles that may be faced during data collection phase. It helps also in estimating time needed to complete the questionnaire form. It was $10 \%$ of staff nurses; the total period for collection of data in the pilot study takes about 15 days. The participants chosen for the pilot study excluded from the study sample.

Reliability was measured using Cronbach's Alpha Coefficients methods to ensure internal consistency and its result revealed that all statements of study questionnaire $\alpha$ were $>0.89$ for time management questionnaire, and $>0.90$ for time waster questionnaire.

C) Filed Work: Implementation of the training program. The data was collected by the researchers, the questionnaires of time management and time wasters distributed to staff nurses as (pretest) before starting the program at morning shift, then post immediately and 3 months after the program. The time needed by each staff nurse to complete questionnaires ranged from 25-30 minutes. The program was implemented six times for six groups of nurses according to the working place of each group. The total time for achieving the whole program to each group was 12 hours for two days ( 3 session's $\times 2$ hours for every day). Each group two days per week.

Different teaching and learning methods used during the sessions included; brain storming, interactive lecture, group discussion, demonstration, and work in small groups.

Actual field work started at the beginning of September 2019 and finished at the end of October 2019. Follow up phase started from beginning of December 2019 with the first group who received the program was at September 2019 to the end of January 2020 with the last group who received the program at October 2019. The researchers contacted with them at their work place.

\section{Ethical considerations}

The research proposal approval was taken from ethical committee at Nursing Faculty Sohag University. Then oral agreement was taken from all participants after explained the purposes of the study and informing them about their rights to participate, refuse, or withdraw at any time. Total confidentiality of any obtained information was ensured. The steps of the study could not entail any harmful effect on participants.

\section{Statistical Analysis}

Data entry and statistical analysis were done using SPSS 19.0 statistical software package. Data were presented using descriptive statistics in the form of frequencies and percentages for qualitative variables. Continuous variables were expressed as mean 
\pm standard deviation. For comparison of categorical variables, the Chi-square test and Pearson Correlation analysis were used for assessment of the

\section{Results}

Table (1): Percentage distribution of the studied nurses according to their characteristics $(n=118)$.

\begin{tabular}{|c|c|c|}
\hline Items & $\mathbf{N}$ & $\%$ \\
\hline \multicolumn{3}{|l|}{ Age (year) } \\
\hline $19-<26$ & 41 & 34.7 \\
\hline $26-<33$ & 44 & 37.3 \\
\hline $33-40$ & 33 & 28 \\
\hline Mean SD & & \\
\hline \multicolumn{3}{|l|}{ Gender } \\
\hline Male & 28 & 23.7 \\
\hline Female & 90 & 76.3 \\
\hline \multicolumn{3}{|l|}{ Marital status } \\
\hline Married & 71 & 60.2 \\
\hline Not Married & 47 & 39.8 \\
\hline \multicolumn{3}{|l|}{ Educational Qualification } \\
\hline Secondary school of nursing Diploma & 77 & 64.7 \\
\hline Technical institute of Nursing & 40 & 33.6 \\
\hline Bachelor Degree of Nursing & 1 & 0.8 \\
\hline \multicolumn{3}{|l|}{ Years of Experience } \\
\hline $1-<10$ & 53 & 44.9 \\
\hline $10-<20$ & 55 & 46.6 \\
\hline $20-<30$ & 10 & 8.5 \\
\hline Mean S.D & & \\
\hline \multicolumn{3}{|l|}{ Department } \\
\hline Medical & 62 & 52.5 \\
\hline Surgical & 56 & 47.5 \\
\hline \multicolumn{3}{|c|}{ Attending Previous training program about time management } \\
\hline Yes & 7 & 5.9 \\
\hline No & 111 & 94.1 \\
\hline
\end{tabular}

Table (2): Compare mean score between studied nurses at pre, post, follow up intervention related time management domains $(\mathrm{N}=118)$.

\begin{tabular}{|c|c|c|c|c|c|}
\hline Domains & No items & $\begin{array}{c}\text { Mean SD } \\
\text { Pre }\end{array}$ & $\begin{array}{c}\text { Mean SD } \\
\text { Post }\end{array}$ & $\begin{array}{c}\text { Mean SD } \\
\text { Follow up }\end{array}$ & $\begin{array}{c}\text { Friedman test } \\
\text { P value }\end{array}$ \\
\hline Goal setting & 6 items & $14.7 \pm 1.31$ & $15.96 \pm 1.58$ & $16.66 \pm 1.03$ & $\begin{array}{c}6.940 \\
.007 * *\end{array}$ \\
\hline Prioritization & 4 items & $9.06 \pm 1.51$ & $9.42 \pm 1.3$ & $9.76 \pm 2.01$ & $\begin{array}{c}3.061 \\
.011^{*}\end{array}$ \\
\hline $\begin{array}{c}\text { Managing } \\
\text { Interruptions }\end{array}$ & 8 items & $17.22 \pm 2.64$ & $18.39 \pm 2.23$ & $20.0 \pm 3.11$ & $\begin{array}{c}7.155 \\
.004 * *\end{array}$ \\
\hline Procrastination & 3 items & $5.98 \pm 1.33$ & $6.68 \pm 1.18$ & $6.76 \pm 1.08$ & $\begin{array}{c}5.088 \\
.009 * * \\
4.023 \\
.010^{*}\end{array}$ \\
\hline Scheduling & 4 items & $8.99 \pm 1.42$ & $9.50 \pm 1.60$ & $10.49 \pm 2.40$ & $\begin{array}{c}7.463 \\
.002 * *\end{array}$ \\
\hline Total & 25 items & $55.95 \pm 8.41$ & $59.95 \pm 7.6$ & $63.67 \pm 9.8$ & \\
\hline
\end{tabular}

\footnotetext{
* Statistical cally significant difference
} 


\section{Total time managemnt}

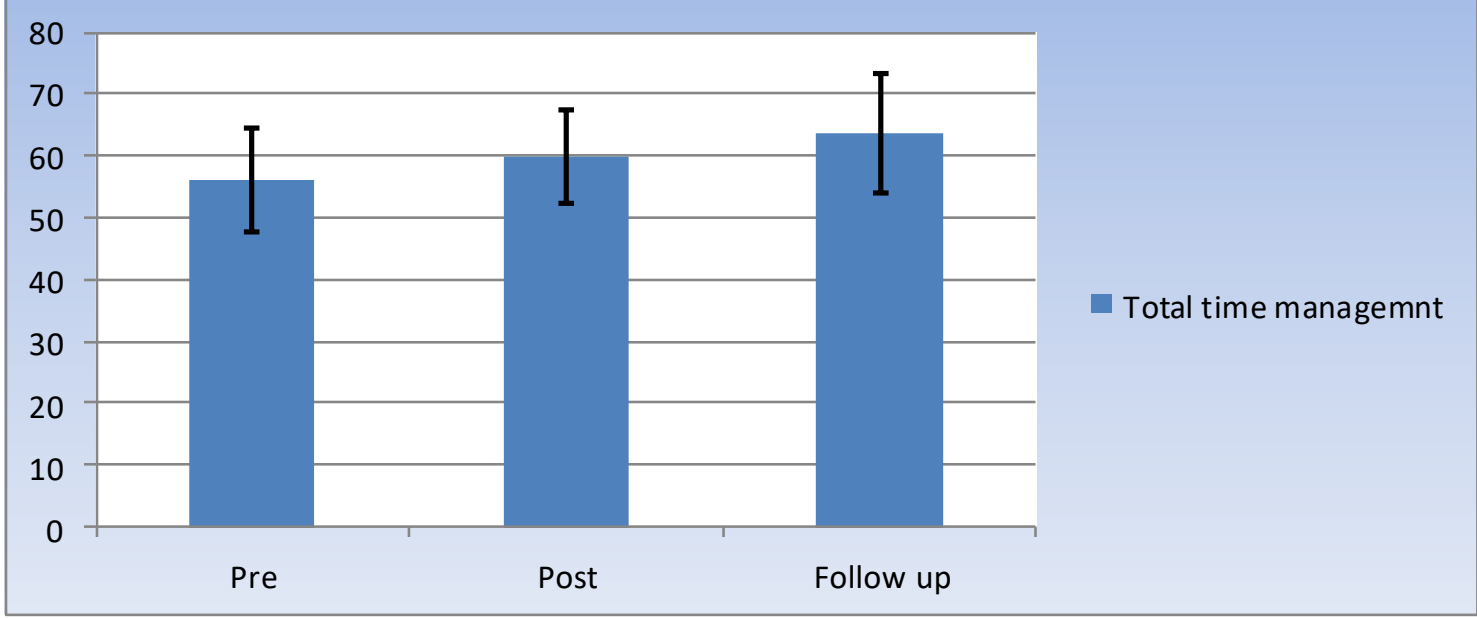

Figure (1): Distribution of mean score between studied nurses at pre, post, follow up intervention related time management domains $(\mathrm{N}=118)$.

Table (3): Compare mean score between studied nurses at pre, post, follow up intervention related time waster domains $(\mathbf{N}=118)$.

\begin{tabular}{|c|c|c|c|c|c|}
\hline Domains & No items & $\begin{array}{c}\text { Mean SD } \\
\text { Pre }\end{array}$ & $\begin{array}{c}\text { Mean SD } \\
\text { Post }\end{array}$ & $\begin{array}{c}\text { Mean SD } \\
\text { Follow up }\end{array}$ & $\begin{array}{c}\text { Friedman test } \\
\text { P value }\end{array}$ \\
\hline $\begin{array}{c}\text { Internal time } \\
\text { waster }\end{array}$ & 8 items & $20.04 \pm 4.84$ & $15.56 \pm 3.46$ & $12.61 \pm 2.00$ & $\begin{array}{c}8.086 \\
.002 * *\end{array}$ \\
\hline $\begin{array}{c}\text { External time } \\
\text { waster }\end{array}$ & 8 items & $21.30 \pm 5.20$ & $16.77 \pm 4.44$ & $12.32 \pm 3.98$ & $\begin{array}{c}7.933 \\
.003 * *\end{array}$ \\
\hline Total & 16 items & $41.34 \pm 9.46$ & $32.32 \pm 7.86$ & $24.93 \pm 5.98$ & $\begin{array}{c}10.103 \\
.000 * *\end{array}$ \\
\hline
\end{tabular}

* Statistical cally significant difference

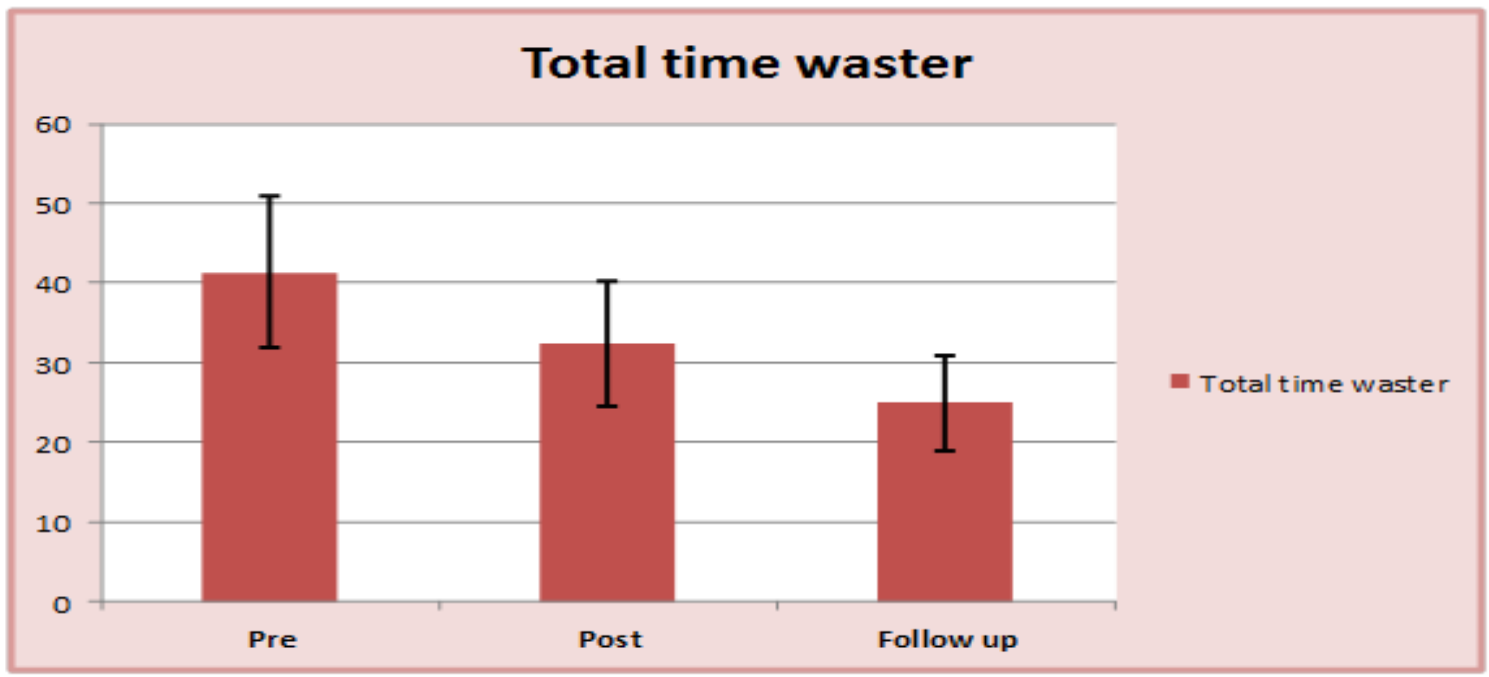

Figure (2): Distribution of mean score between studied nurses at pre, post, follow up intervention related time waster domains $(\mathrm{N}=118)$ 
Table (4): Correlation between studied variables at post intervention.

\begin{tabular}{|l|l|l|}
\hline & & \\
\hline \multirow{2}{*}{ Time waster } & r. & -0.439 \\
\cline { 2 - 2 } & $\mathrm{p}$ & $0.009 * *$ \\
\hline
\end{tabular}

* Statistical cally significant difference

Table (5): Multiple Linear regression model.

\begin{tabular}{|c|c|c|c|c|}
\hline & $\begin{array}{c}\text { Unstandardized } \\
\text { Coefficients }\end{array}$ & $\begin{array}{c}\text { Standardizd } \\
\text { Coefficients }\end{array}$ & \multirow[t]{2}{*}{$\mathbf{T}$} & \multirow{2}{*}{$\begin{array}{c}P . \\
\text { value }\end{array}$} \\
\hline & \multicolumn{2}{|l|}{$|B|$} & & \\
\hline Age & .178 & .129 & 3.161 & $.010^{*}$ \\
\hline Educational level & .577 & .436 & 8.117 & $.001 * *$ \\
\hline Experience & .369 & .294 & 5.102 & $.003 * *$ \\
\hline Previous training & .411 & .364 & 7.606 & $.001 * *$ \\
\hline Time management & .439 & .382 & 8.213 & $.000 * *$ \\
\hline \multicolumn{5}{|l|}{ ANOVA } \\
\hline Model & Df. & $\mathbf{F}$ & \multicolumn{2}{|c|}{ P. value } \\
\hline Regression & 5 & 10.556 & \multicolumn{2}{|c|}{$.000 * *$} \\
\hline
\end{tabular}

* Statistical cally significant difference

a. Dependent Variable: Time waster

b. Predictors: (constant) Age, Educational level, Experience, Previous training and Time management

Table (1): Demonstrats that mean age of study nurses was $(28.5 \pm 6.3)$, about $(76.3 \%)$ of them were female. Related to marital status, $(60.2 \%)$ of them were married. Regarding educational level, (64.7\%) of studied nurses had secondary school of nursing. Also, this table shows means score of study nurses was $(9.94 \pm 6.2)$ and about $(94.1 \%)$ of them did not attended training courses about time management.

Table (2): There was high statistical significant difference between studied nurses at pre, post and follow up intervention related goal setting, managing interruptions, procrastination domains of time management at p-value $<0.01$,. While, there were slight differences between studied nurses related to prioritization and scheduling domains at $\mathrm{p}$ value $<0.05$.

Figure (1): Demonstrats that mean score of total time managements at pre intervention was (55.95 \pm 8.41$)$, post intervention was $(59.95 \pm 7.6)$, and follow up was (63.67 \pm 9.8$)$.

Table (3): There was high statistical significant difference between studied nurses at pre, post and follow up intervention related to internal and external time wasters domains at $\mathrm{p}$-value $<0.01$.

Figure (2): Demonstrats that mean score of total time wasters at pre intervention was (41.34 99.46$)$, post intervention was $(32.32 \pm 7.86)$, and follow up was $(24.93 \pm 5.98)$.

Table (4): Reveals that there was high negative correlation and statistical significant difference between time management scores and time wasters scores at $\mathrm{p}$ value $<0.01$.

Table (5): Reveals that age had slight positive predictor effect on time wasters at p-value .010. While, educational level, experience, previous training and time management had high positive predictor effect on time wastes. There was high statistical significant difference at $\mathrm{p}$ value $<0.01$

\section{Discussion}

Due to the rapid change in the work environment, especially the healthcare environment, nurses need to master time management skills in an effective way to meet patients' needs and increase productivity. The graduates nurses must have good time management skills, along with professionalism and effective communication skills, are among the most important foundations for success (Blevins \& Millen, 2016). To practice the profession of nursing and perform work with high efficiency, nurses must have good time management skills, knowledge and application of various time management strategies at work. (Said, 2014). This study was conducted with the aim to evaluate the effect of a designed program of time management on daily time waters for nurses'. The present study depicts that, about third of the study sample aged from 26 to less than 33 year old, the majority of them were female, about two third of them married and have diploma of nursing school, slightly less than half of them their experience from 
10 to less than 20 years, and most of them reported no previous training program attended.

The present study indicated that there were high statistical significances differences between studied nurses at pre, post and follow up intervention related goal setting, managing interruptions, and procrastination domains of time management table (2). This result agrees with the results of (Elsabahy et al., 2015) they revealed that, there was a high statistical significance difference in time management behavior $\mathrm{p}-\leq 0.001$ before and after implementing the program. Also, this results consistence with this result of (Reference of business, 2015) revealed that, highly statistical significances differences and improvement of head nurses' skills of time management post implementation the program, and their skills which improved post program were in setting goals, determine priorities, making scheduling, overcome procrastination, managing interruptions, and using delegation. And agreed with (Ebrahimi, et, al., 2014) they found that, there was a highly statistical significances differences for staff nurses' and head nurses 'perception for time management behaviors of nursing personnel, and clarified that manage the time effectively is very important for all managers to achieve the goals in an organization. This result may be due to staff nurses after training program implement the time management skills in their practices and used as a habit such as; setting goals, managing interruptions, and avoid procrastination.

Also, the study found that there was slight difference between studied nurses related prioritization and scheduling domains of time management. This study in consistent with (Nasri et al., 2013), they stated that, the behavior of time management for all elements of the time management behavior "planning (setting objectives, and setting priorities), organizing, scheduling, and controlling" among head nurses improved immediately after program implementation. This result may be related to no standard formats to save time which include time management tools which help staff to manage their time in the organization.

The result of present study revealed that, there was high significant difference between studied nurses at pre, post and follow up intervention related to internal and external time wasters domains (table 3). The results were disagreement with (Amer, 2015) recommended that, about two third from head nurses were rarely or never time wasters post program in relation to half of them preprogram, this related to head nurses post program identified the time wasters as; unclear purpose and unable to set priorities at work; procrastination; disorganized work area and increase the paper work due to there is no good information system; fail to work as a team and unable to manage conflict arising in the unit; unable to say "No" when they have work overload and make a lot of telephone call during work, and lack of feedback; and they identified how to overcome this time wasters. This result may be related to most of staff before program have difficult to control in both internal and external time wasters but after the program they known the strategies for time management which decrease this time wasters.

Current study result indicated that, there was highly negative correlation between time management scores and time waster scores at p-value $<0.01$ (table 4). In contrary with this results (Mohamed, 2016) who recommended that, must be provide staff development programs to head nurses with emphasis on time management skills and implement time management strategies for saving time and overcome time wasters, because he found about half of the head nurses in his study have time wasters and he said this time wasters were due to unable to set objectives, poor planning, more socializing and telephone interruptions, procrastination, ineffective and unorganized meeting, , lack of information which need to take decision, poor communication in the organization, lack of feedback, inadequate described organizational policies and procedures, incompetent coworkers, inability to delegate in effective way, inability to say no, and sometimes paper work increased. And this findings support by, (Häfner et al., 2014) they found that, time management training program improves the perceived control of time and a decrease in perceived stress at work but it had no effect on the different performance indicators. This result may be related to the effective of the program which leads to increase the awareness of staff nurses about time management skills and how they can decrease their daily time wasters.

The study furthermore revealed that age had slight positive predictor effect on time waster. (Table 5). (El-Shaer, 2015) opposed the result he found that, negative correlation were found pre and post program between head nurses age, experience with their level of knowledge, current use of time management behaviors, time wasters and their perception toward effective organizational performance. This result may be due to the staff nurses old age were more mature to identifying the different types of time waters and how can decrease it.

Also, the study found that educational level, experience, previous training and time management had high positive predictor effect on time wasters. (Table (5). This findings are agreement with the study conducted by (Marques \& Huston, 2012) they reported that increase the experience of the head nurses help them to use time estimation to organize 
their work effectively within time constrains, and deal with time wasters especially external time wasters as in overload paper work. This result may be due to the staff nurses with more experiences have abilities to evaluate and determine the time wasters and able to take a good decision to decrease it.

\section{Conclusion}

The current study concluded that:

1. There were high negative correlation between time management scores and time waster scores.

2. There was high significant difference between studied nurses at pre, post and follow up intervention related goal setting, managing interruptions, procrastination domains.

3. There was high significant difference between studied nurses at pre, post and follow up intervention related internal time waster and external time waster domains.

4. The age had slight positive predictor effect on time wasters while educational level, experience, previous training and time management had high positive predictor effect on time waster.

\section{Recommendations}

1. Should be provided training programs on time management skills for nursing personnel at all levels in healthcare organizations to optimize the use of time management behaviors achieve effective organizational performance and reduce wasting time.

2. Organizational records should be standardized and clear models for saving time, and should be include effective time management tools such as; record the time, schedule, daily and weekly time planning to help staff to manage their time in a good way.

3. The organizational policies, rules and regulations should be clear and available to all nursing staff to save time.

4. Personnel in the organization at all levels should be aware of the importance of good time management practices and use as a habit of work such as; How to set goals and prioritize activities, using the task list and effective delegation, and avoid procrastination and overcoming it to provide an opportunity for competition

5. Meetings must be carefully defined and organized by predetermining the goals of the meeting, the required time, place and target of attendance, and the important points addressed by the meeting, to helps in saving time

\section{References}

- Adeyinka, A., (2012): Effective time management for high performance in an organization. Business School Degree programmer in Business Administration International Business. IOSR Journal of Nursing and Health Science (IOSRJNHS) e-ISSN: 2320-1959.p- ISSN: 2320-1940 Volume 4, Issue 3 Ver. II (May. - Jun. 2015), PP 18-30 www.iosrjournals.org

- Al-Zoubi, M., (2016): The Effect of the Time Management Art on Academic Achievement among High School Students in Jordan. Journal of Education and Practice. ISSN 2222-1735 (Paper) ISSN 2222-288X (Online) Vol.7, No.5, 2016.

- Amer, W., (2015): The Impact of Implementing Time Management Strategies on Achieving Operational Plans (An applied study on the General Personnel Council Staff in Gaza Strip). Thesis is Master Degree of Business Administration. Islamic University of Gaza Deanship of Higher Education Faculty of Commerce Department of Business Administration. P. p 1-39

- Ancel, G., \& Yilmaz, Y., (2016): Time management in Turkish nurses. Global Journal on Humanites \& Social Sciences. 205-2011.

- Blevins, S., \& Millen, A., (2016): Foundation for New Graduate Nurse Success. MEDSURG Nursing, 194196

- Chapman, S., \& Rupured, M. (2018): Time management; 10 strategies for better time management. The University of Georgia and Cooperative Extension, College of Agricultural and Environmental Sciences, Family and consumer Sciences, 2008.

- Darden, D., (2015): Time Wasting Activities within the Workplace: Don't Be A part of Them. Tiffin University, Tiffin, OH, USA. Email: derrick.c.darden@gmail.com.

- Ebrahimi, H., Hosseinzadeh, R., Tefreshi, M., \& Hosseinzadeh, S., (2014): Time management behaviors of head nurses and staff nurses employed in Tehran Social Security Hospitals, Iran in 2011.19(2): 193 -Iranian Journal of Nursing and Midwifery Research. Located at: http://www.ncbi.nlm.nih.gov/pmc/articles/PMC402 0030/. Accessed on: 12/5/2014.

- Elsabahy, H., Sleem, W., \& El Atroush, H.(2015): Effect of Time Management Program on Job Satisfaction for Head Nurses Journal of Education and Practice www.iiste.org ISSN 22221735 (Paper) ISSN 2222-288X (Online) Vol.6, No.(32). p.p $36-44$.

- El-Shaer, A., (2015): Impact of Time Management Program on Time Wasters of Head Nurses and Their Perception toward Effective Organizational Performance. IOSR Journal of Nursing and Health 
Science (IOSR-JNHS) e-ISSN: 2320-1959.pISSN: 2320-1940 Volume 4, Issue 3 Ver. II (May. Jun. 2015), PP 18-30.

- Ghiasvand, A., Naderi, M., Tafreshi, Z., Ahmadi, F., \& Hosseini, M., (2017): Relationship between time management skills and anxiety and academic motivation of nursing students in Tehran. Electronic physician, 36783684

- Gordon, E., \& Borkan, C., (2014): Recapturing time: a practical approach to time management for physicians. Postgrad Med J, 267-272.

- Häfner, A., Stock, A., \& Oberst, V., (2014): Decreasing students' stress through time management training: an intervention study. Eur J Psychol Educ. 2014 DOI 10.1007/s10212-0140229-2.

- Kaya, H., Kaya, N., Pallos, Ö, \& Kucuk L., (2012): Assessing time-management skills in terms of age, gender, and anxiety levels: A study on nursing and midwifery students in Turkey. Nurse Education in Practice, 3, 284-288.

- Mohamed, N., (2016): Time management among head nurses at Mansoura University Hospitals. Journal of Higher Institute of Public Health.36 (21)2006:539-554.

- Marques, B., \& Huston, C., (2012): Leadership roles and management functions in nursing; theory and applications. Wolters Kluwer, Lippincott Williams \& Wilkins, Philadelphia; 2012; $6^{\text {th }}$ ed.:186-200.

- Nasri S., Pazargadi M., Tafreshi M., \& Nassiri, N., (2013): The Correlation of Head Nurses' Time Management with Nurses' Job Satisfaction in Medical \& Surgical Wards of Hospitals in Arak Medical Sciences University. Journal of Nursing and Midwifery, 22 (79)

- Nayak, S., (2019): Time Management in Nursing Hour of need. International Journal of Caring Sciences September-December 2018 Volume 11। Issue 3| Page 1997.

- Reference of business. Time Management (2015): Encyclopedia of Business, $2^{\text {nd }}$ ed. » $\mathrm{Str}-\mathrm{Ti}$ » [53].

- Said, B., (2014): Time Management in Nursing Work. International Journal of Caring Sciences, 2, 746-749.

- Sergio, A., (2012): Time management for health professions students'. Oshpd, office of Statewide Health Planning and Development, Healthcare Workforce Development Division. Page 2 -14.

- Tavakoli, H., Tavakoli, A., \& Pouresmaeil, L., (2013): A Study of the Relationship between Time Management and Job Satisfaction. International Journal of Research in Organizational Behavior and
Human Resource Management, Vol. 1, No. 3,: 6674

- Woodcock, B., (2014): How to manage your time effectively. Page maintained by B.E.Woodcock@kent.ac.uk (available at 15-102014).

- Zucas, B., \& David, H., (2012): Definition of Time Management. http://www free timemanagement. tips.com/d.2012. 